\title{
AS MEMÓRIAS ESCOLARES NO MUSEU HISTÓRICO UNIVERSITÁRIO
}

\author{
Aline Antunes Zanatta ${ }^{1}$ \\ Museu Republicano “Convenção de Itu”/MP/USP \\ zanatta@usp.br
}

\section{INTRODUÇÃO}

Localizado na cidade de Itu, interior do Estado de São Paulo, o Museu Republicano “Convenção de Itu” foi inaugurado pelo presidente do Estado de São Paulo, Washington Luís Pereira de Sousa, a 18 de abril de 1923 e desde então subordinou-se administrativamente ao Museu Paulista (o popularmente conhecido Museu do Ipiranga) que, em 1934, tornou-se instituto complementar da recém-criada Universidade de São Paulo e a ela integrou-se em 1963 (BREFE, 2005, p. 165).

Segundo Ana Claudia Brefe, Afonso d'Escragnolle Taunay ficou responsável pela organização e direção dessa instituição, cuja formação coincidiu com a comemoração do cinquentenário da Convenção de Itu, em 18 de Abril de 1923 (BREFE, 2005, p. 165). A reunião política aconteceu no sobrado do museu em 18 de abril de 1873 e teve como objetivo discutir a organização do Partido Republicano Paulista, constituído em grande parte por proprietários agrícolas.

Em 1923, inaugurado o Museu, inúmeras doações lhe foram feitas, vindas principalmente dos membros do Partido Republicano Paulista. Em suas primeiras aquisições, Taunay encomendou retratos dos "Convencionais" e dos integrantes do primeiro governo republicano do país, assim como obteve de famílias ituanas o mobiliário, lustres, tapetes e objetos de decoração. Preocupado com a história local, passou a adquirir peças e iconografia do passado ituano.

Atualmente, a professora Maria Aparecida de Menezes Borrego é a supervisora e o processo de curadoria desses acervos é realizado por professores, especialistas e técnicos, cuja finalidade reside em cuidar do acervo, disponibilizar instrumentos para pesquisa e desenvolver projetos, além de ações educativas.

\footnotetext{
${ }^{1}$ Doutoranda em Educação pela Faculdade de Educação da Universidade Estadual de Campinas - UNICAMP.
} 
Cabe destacar que somente em 2006 uma profissional foi contratada especialmente para organizar o serviço educativo da instituição.

Considera-se a educação em museus um campo de conhecimento em construção, podendo ser compreendido a partir do campo da educação não formal. Segundo Jaume Trilha, a educação não formal consiste em toda aquela mediada pela relação ensino-aprendizagem, tem forma, assume e desenvolve metodologias com procedimentos e ações diferenciadas das adotadas nos sistemas formais e, estruturalmente, não tem uma legislação nacional que a regule e incida sobre ela. Atuando a partir de programas, propostas e projetos, mas organizam-se e estruturam-se com inúmeros diferenciais (TRILHA, 1996).

Neste sentido, esta pesquisa pode colaborar com a compreensão das potencialidades dos acervos escolares, produzidos nos espaços formais de educação, podem ser mobilizados em museus de história.

Entre 2006 e 2007 foram realizados estudos sobre o público do museu para que o serviço fosse organizado. Neste momento, foi apontado a pouca presença dos estudantes locais entre os visitantes do museu. Desta forma, iniciou-se o serviço educativo, retomando a relação entre o museu e o os estudantes da cidade, em especial, as escolas localizadas na área envoltória do museu. Cabe lembrar que o Museu Republicano está localizado no Centro Histórico da cidade de Itu, formado aproximadamente por 240 imóveis.

Logo, a partir de 2008, foram centralizadas as ações junto às escolas próximas ao museu, desenvolvendo atividades dentro das instituições de ensino formais e organizando projetos multidisciplinares de extensão universitária. Destaca-se que neste momento passamos a nos valer dos acervos escolares como possibilidade de aproximação entre o público e o museu, considerando estes acervos ricos no entendimento da sociedade a partir da história do cotidiano e do trabalho. Cabe advertir que o professor Ulpiano Bezerra de Meneses, no artigo "A cidade como bem cultural: áreas envoltórias e outros dilemas, equívocos e alcance da preservação do patrimônio ambiental urbano", ressaltou que as relações do cotidiano e do trabalho não foram abordadas enquanto patrimônios durante um longo período pelas instituições brasileiras de preservação (IPHAN, 2006). 


\section{AS MEMÓRIAS ESCOLARES}

Os acervos escolares ganharam destaque dentre os projetos de pesquisa e difusão desenvolvidos pelo museu, entre 1 de abril de 2008 e 1 de abril de 2009. Mais precisamente, a partir do "Projeto Arquivo Escolar e Memória Social"2, que recebeu o apoio do programa de fomento da Pró-Reitoria de Cultura e Extensão Universitária da Universidade de São Paulo.

O acervo arquivístico do Museu Republicano é formado por documentos manuscritos que possibilitam a pesquisa em temas relacionados à história da cidade de Itu e região desde meados do século XVIII a 1950, e estão sob a curadoria da Dra. Anicleide Zequini. Em 2005, em função da doação ao Museu Republicano da Biblioteca Edgard Carone, uma parceria entre a USP e a Prefeitura Municipal possibilitou que, através de comodato, o edifício conhecido como "Casa do Barão" se tornasse o Centro de Estudos do Museu Republicano, local em que foram instalados a biblioteca, o arquivo e o auditório da instituição. Neste contexto, as coleções documentais do museu e arquivo municipal de Itu foram acondicionadas no arquivo do Museu Republicano.

Entre esses conjuntos que pertencem ao arquivo municipal, destacam-se dois fundos de arquivo que possibilitaram o desenvolvimento do projeto sobre acervos escolares. Trata-se de documentos referentes aos dois primeiros grupos escolares que foram instalados na cidade de Itu: o Grupo Escolar Convenção de Itu, fundado em 1916, e o Grupo Escolar Dr. Cesário Motta, inaugurado em 1894.

O fundo Grupo Escolar Cesário Motta (com 331 unidades de documentos) abrange documentos que contemplam o período entre 1894 a 1974. Neste conjunto, encontra-se: registros de frequências, de visitas, de matrículas, listagens do acervo da biblioteca, recortes de jornais sobre a escola, jornais comemorativos, regulamentos, correspondências, planejamento pedagógico e um número significativo de fotografias.

\footnotetext{
${ }^{2}$ Projeto de pesquisa e de extensão desenvolvido, entre 2008 e 2009, pelo serviço educativo e o arquivo textual do Museu Republicano Convenção de Itu. Relatório de Aplicação de Recursos apresentado em 2009 à Pró-Reitoria de Cultura e Extensão da Universidade de São Paulo, que contém fotos e textos sobre o projeto.
} 
FIGURA 1: $50^{\circ}$ Aniversário do Grupo Escolar Cesário Mota.

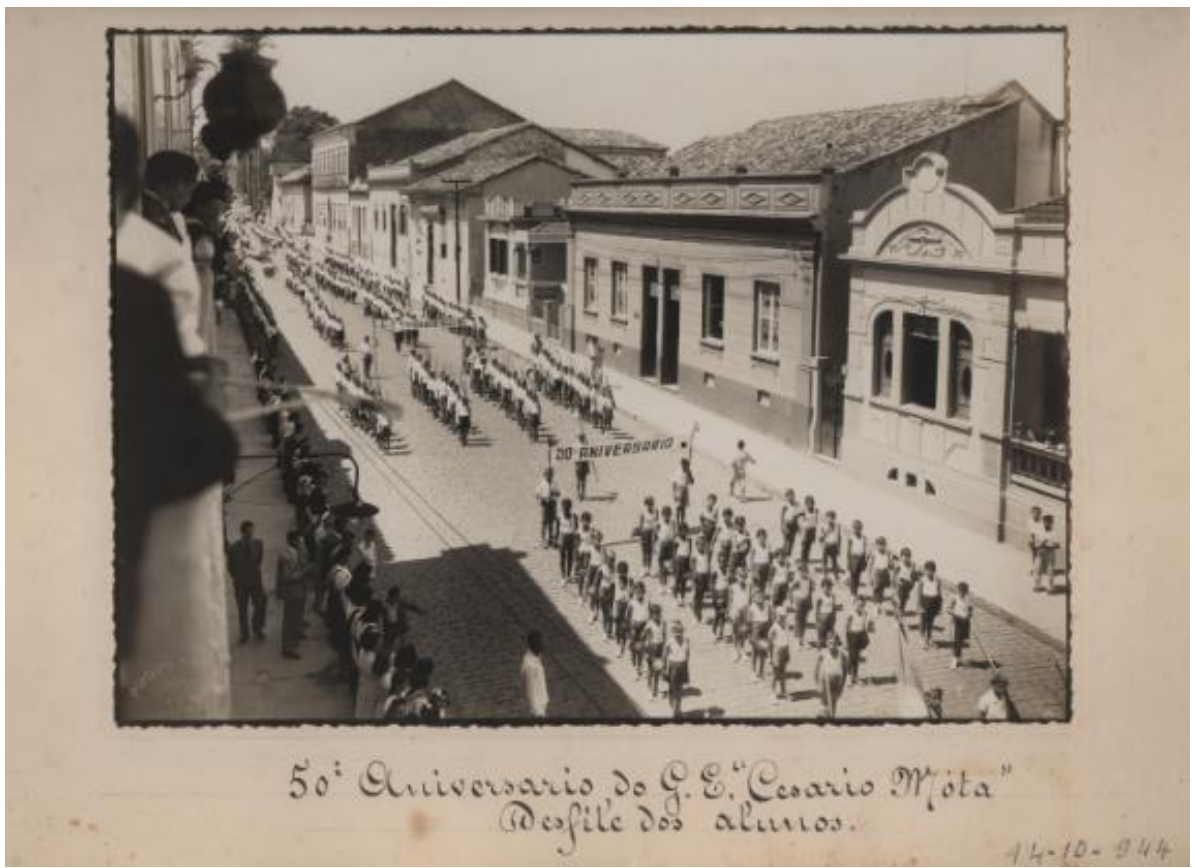

Fonte: Museu e Arquivo Histórico Municipal de Itu/MRCI/MP/USP. Fundo Grupo Escolar Cesário Motta.

FIGURA 2 - Museu do Grupo Escolar Cesário Motta.

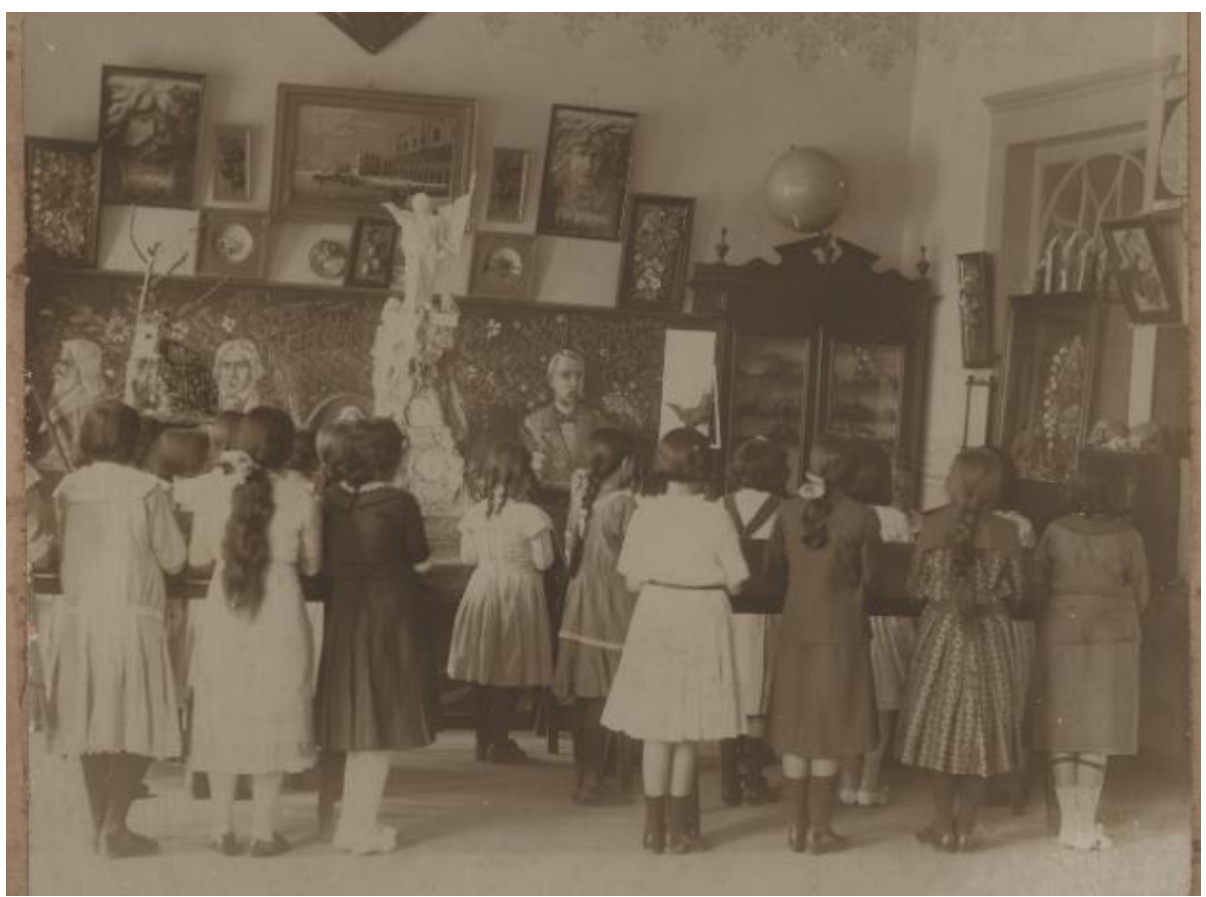

Fonte: Museu e Arquivo Histórico Municipal de Itu/MRCI/MP/USP. Fundo: Grupo Escolar Cesário Motta. 
FIGURA 3 - Museu do Grupo Escolar Cesário Motta.

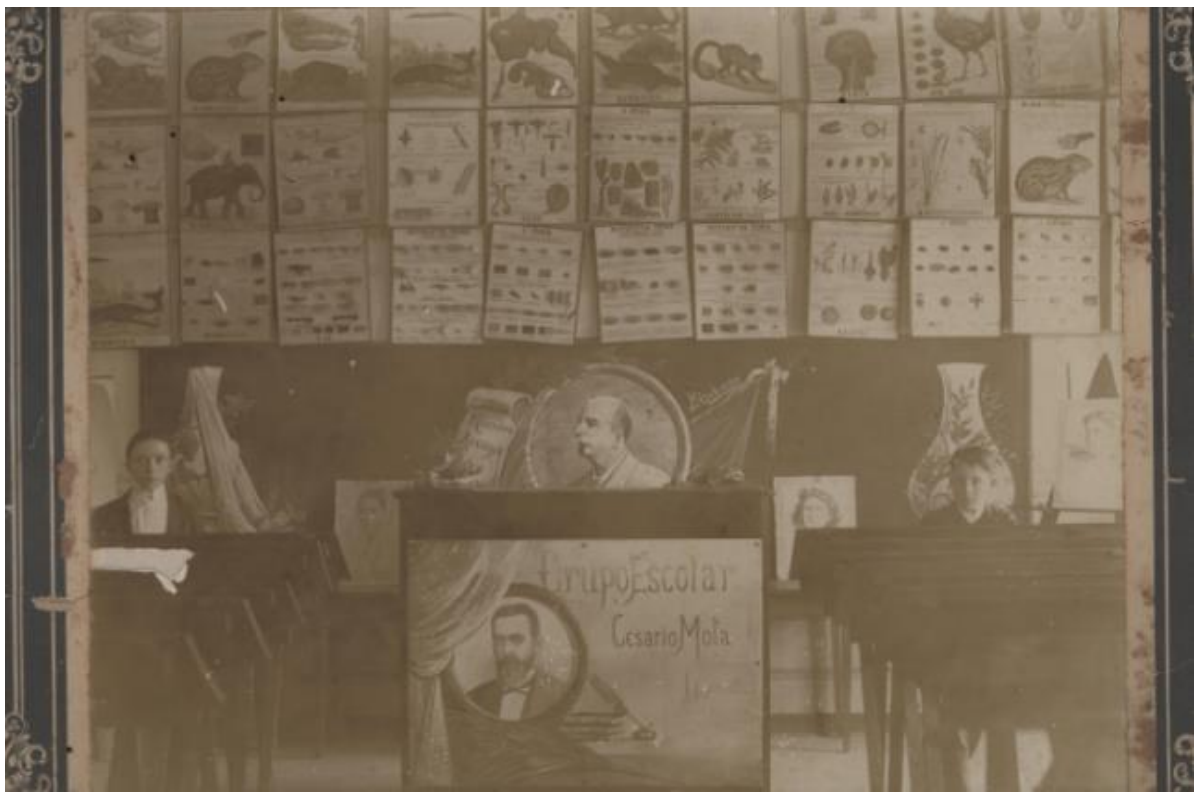

Fonte: Museu e Arquivo Histórico Municipal de Itu/MRCI/MP/USP. Fundo Grupo Escolar Cesário Motta.

FIGURA 4 - Sericultura. Grupo Escolar Cesário Motta, Início do século XX.

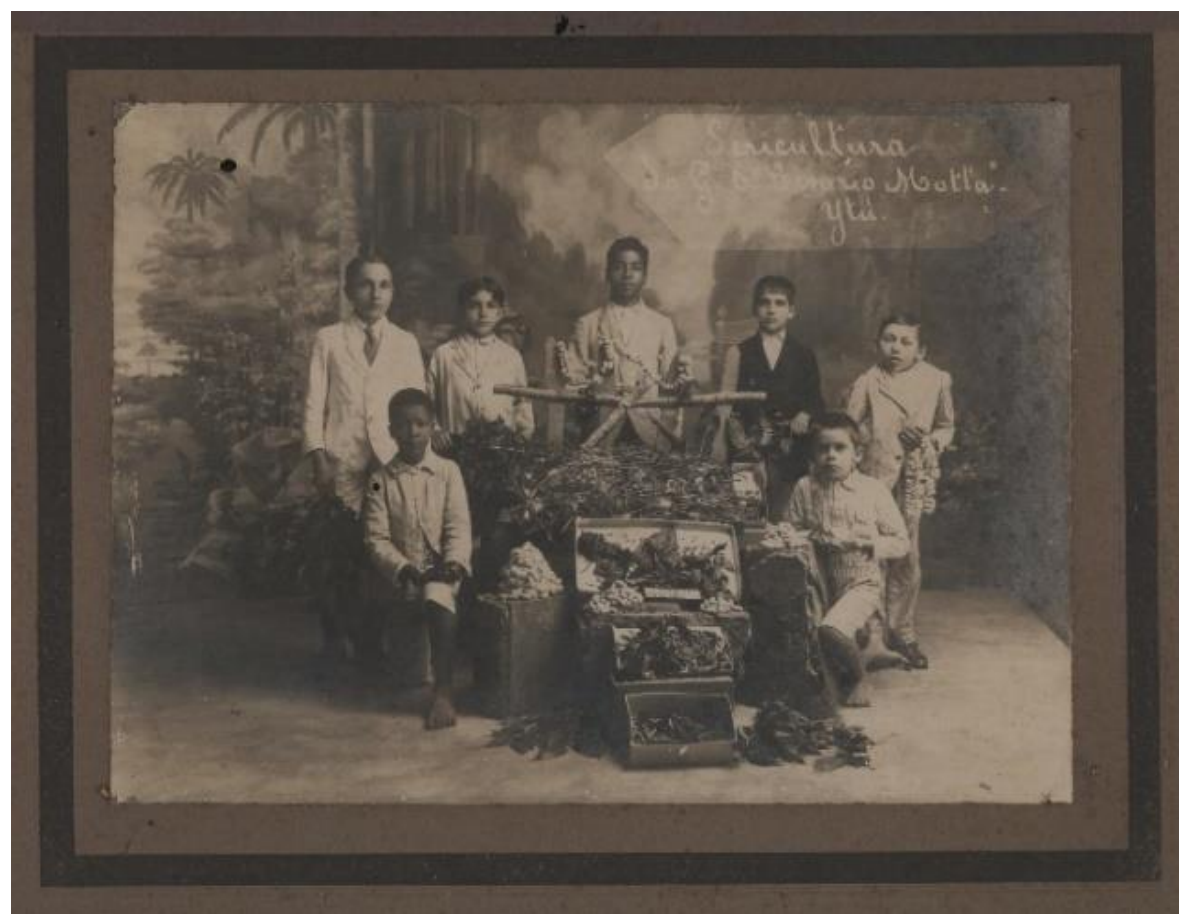

Fonte: Museu e Arquivo Histórico Municipal de Itu/MRCI/MP/USP.

Fundo Grupo Escolar Cesário Motta. 
Já no fundo Grupo Escolar Convenção de Itu (com 207 unidades de documentos) encontram-se documentos desde o período da fundação da escola, em 1916, até o ano de 1975. O conjunto é composto de: atas de reuniões pedagógicas, jornais produzidos pela escola, recortes de jornais, planta do edifício, livro-ponto dos funcionários, de frequência dos alunos, documentos de caixa de assistência, registros da biblioteca, documentos da caixa de assistência escolar, regulamentos e livros de inventário (mobiliário e materiais de consumo).

FIGURA 5 - Consultório Dentário do Grupo Escolar “Convenção de Itu”.

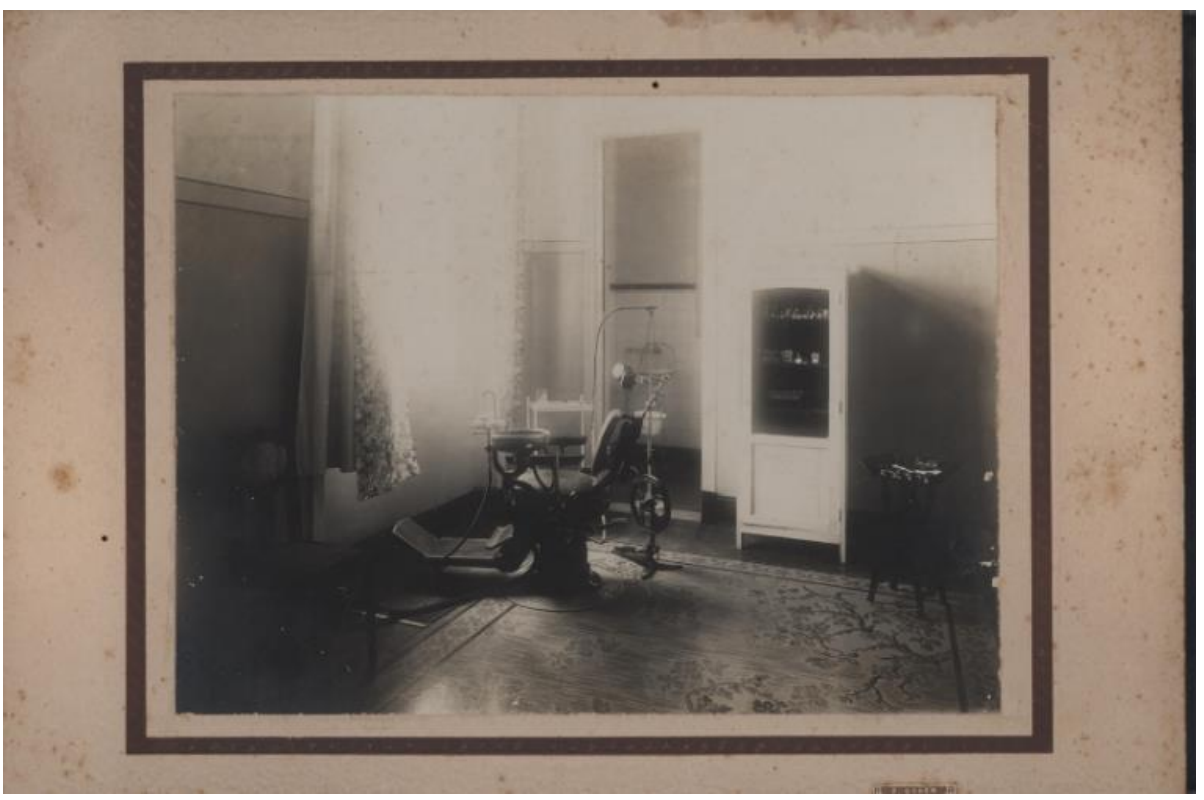

Fonte: Museu e Arquivo Histórico Municipal de Itu/MRCI/MP/USP. Fundo Grupo Escolar "Convenção de Itu”.

Para tanto, a partir do projeto “Arquivo Escolar e Memória Social”, o serviço educativo e o arquivo de documentação textual e iconográfica do Museu Republicano organizaram e confeccionaram um material educativo, composto por reproduções de documentos textuais e iconográficos relativos às instituições escolares mencionadas, acompanhadas por instrumentos de pesquisa. Esse material foi acondicionado em suporte original: uma maleta, confeccionada especialmente para essa finalidade, tendo em vista disponibilizar a educadores subsídios para trabalhos em sala de aula. Para acompanhar, foram produzidos três cadernos pedagógicos escritos por Aline Zanatta e Anicleide Zequini. 
FIGURA 6: Material Educativo do Museu Republicano.

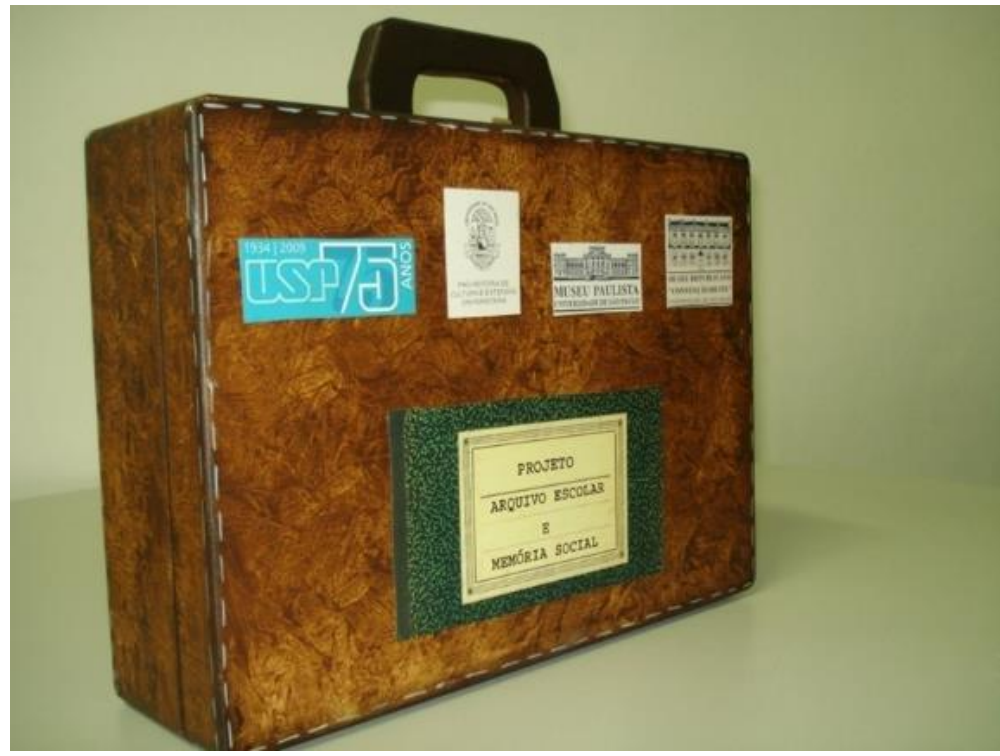

Fonte: Relatório de Aplicação de Recursos apresentado em 2009 à Pró-Reitoria de Cultura e Extensão da Universidade de São Paulo.

FIGURA 7 - Material Educativo do Museu Republicano.

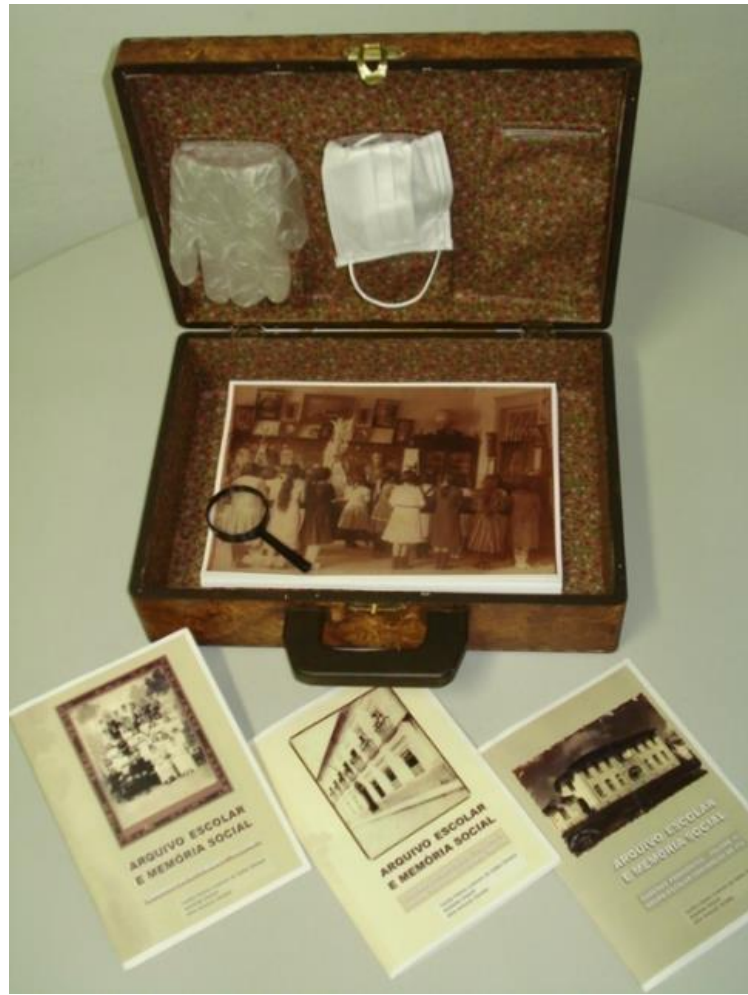

Fonte: Relatório de Aplicação de Recursos apresentado em 2009 à Pró-Reitoria de Cultura e Extensão da Universidade de São Paulo. 
No primeiro volume, procurou-se mostrar os objetivos do projeto e a importância da documentação produzida pela escola e na escola. Para tanto, foi apresentado um breve relato sobre a formação dos grupos escolares brasileiros, propondo atividades que explorassem essa dimensão da prática de conhecimento no campo da História. O segundo transcorre sobre a trajetória dos grupos escolares na cidade de Itu, em especial do Grupo Escolar "Cesário Motta". Já o terceiro, abordou o Grupo Escolar "Convenção de Itu”, o segundo grupo escolar da cidade.

No bojo das discussões acerca do patrimônio educativo, o primeiro volume enfatizou, com as sugestões de atividades aos educadores, a necessidade do envolvimento dos vários sujeitos na construção das narrativas. Já os demais volumes, preocupam-se com a trajetória dos dois grupos escolares.

Paralelamente à organização do material educativo, foram oferecidas aos educadores visitas técnicas e dois cursos de difusão cultural, tendo por finalidade discutir a constituição e o conteúdo didático do material proposto. Neste sentido, buscamos um diálogo com a comunidade escolar, em especial com os professores das escolas Cesário Motta e Convenção de Itu, para a definição da composição do material.

FIGURA 8 - Curso de Extensão - Modalidade Difusão Cultural - 2010.

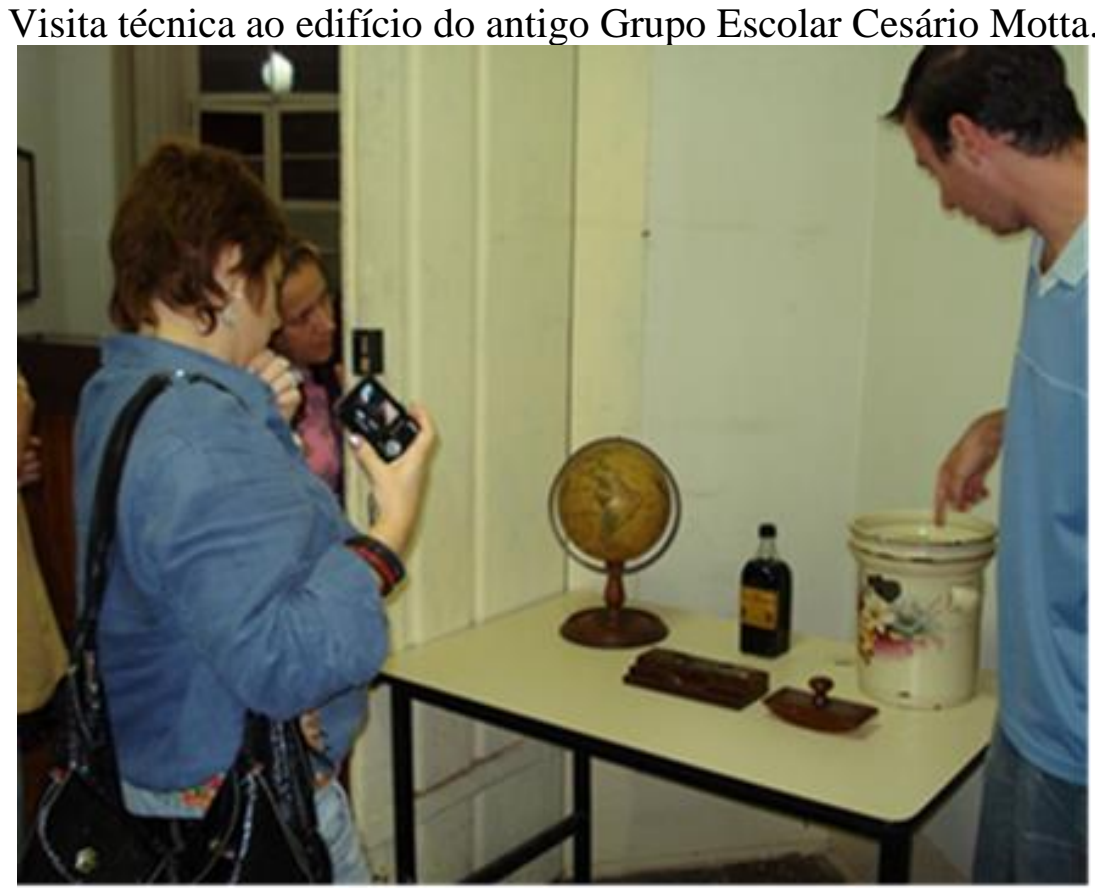

Fonte: Relatório de Aplicação de Recursos apresentado em 2009 à Pró-Reitoria de Cultura e Extensão da Universidade de São Paulo. 
A partir da realização do projeto "Arquivo Escolar e Memória Social”, foi elaborado um material didático voltado para realização de oficinas junto aos educadores das escolas da rede pública localizadas na área do Centro Histórico da Cidade de Itu/SP, visando ampliar as relações entre o Museu Republicano e os educadores, estimular a exploração do espaço museológico para o enriquecimento do conteúdo de história ministrado nas escolas e sensibilizar os professores e alunos para a relação entre as práticas cotidianas e patrimônio histórico-cultural, evidenciando a importância dos museus de história na criação e difusão de novos saberes, bem como no desenvolvimento de práticas educativas específicas que instituições como essas podem oferecer para a produção e preservação do patrimônio educativo.

Os acervos produzidos nos ambientes escolares e sobre as escolas foram novamente mobilizados em exposições temporárias no Museu Republicano em 2013, 2014 e 2015.

\section{EXPOSIÇÕES}

Em 2013, o serviço educativo, ao realizar uma pesquisa sobre os estabelecimentos comerciais e instituições de ensino e da sociedade civil com o objetivo de compreender a circulação da palavra "convenção" na cidade de Itu, fez a curadoria de uma exposição temporária chamada "Imagens da Convenção: circulações contemporâneas".

Foram apresentados, em acordo de empréstimo do acervo da escola, quadro comemorativo com fotografias dos primeiros professores do Grupo Escolar Convenção de Itu, flâmula. Além de acervos do fundo de arquivo do grupo escolar existente no museu. 
FIGURA 9 - Fotografia da Exposição “Imagens da Convenção: circulações contemporâneas”. Relatório do Museu Republicano. 2013.

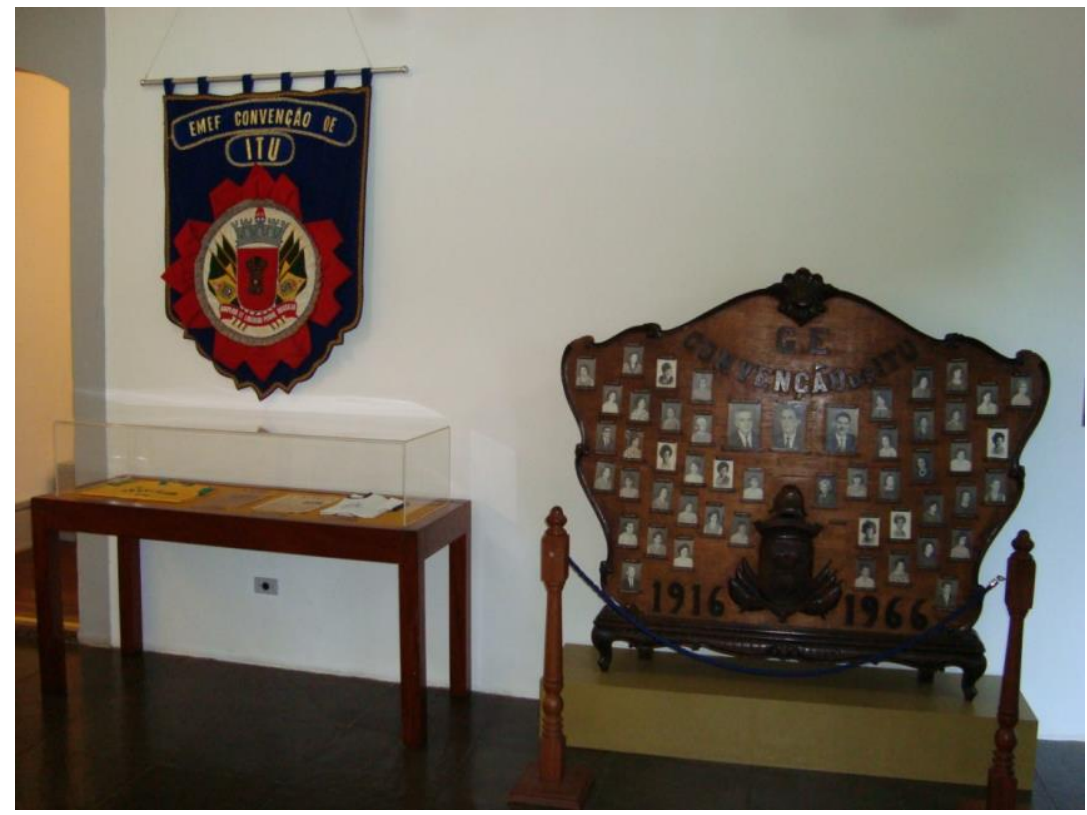

Fonte: Serviço Educativo do Museu Republicano Convenção de Itu/MP/USP.

Desta ação, o museu recebeu a doação de uma camiseta de estudante que foi exposta e hoje encontra-se em nossa reserva.

Outra exposição importante, produzida pelo serviço educativo e arquivo do museu, ocorreu em setembro de 2013, sobre a trajetória da Escola Infantil Municipal Maria Antônia Luporine Sampaio. A escola, fundada em 1943, tinha inicialmente como nome Escola Operária Santo Inácio, localizada até os dias de hoje na rua Paula e Souza em Itu. Nas primeiras décadas contou com a direção e dedicação de dona Maria Antonia Luporine Sampaio, à época conservadora do Museu Republicano.

Mais do que acompanhar a construção da escola infantil, a mostra temporária apresentou ao público a atuação da antiga funcionária do Museu Republicano junto à escola, não somente coordenando as atividades voltadas para as crianças carentes, mas, sobretudo, oferecendo aulas noturnas de alfabetização às jovens operárias das fábricas de tecidos da cidade de Itu. Apresentouse ao público um conjunto de reproduções de imagens cedidas pela escola ao museu. 
FIGURA 10 - Maria Antônia lecionando no curso de alfabetização.

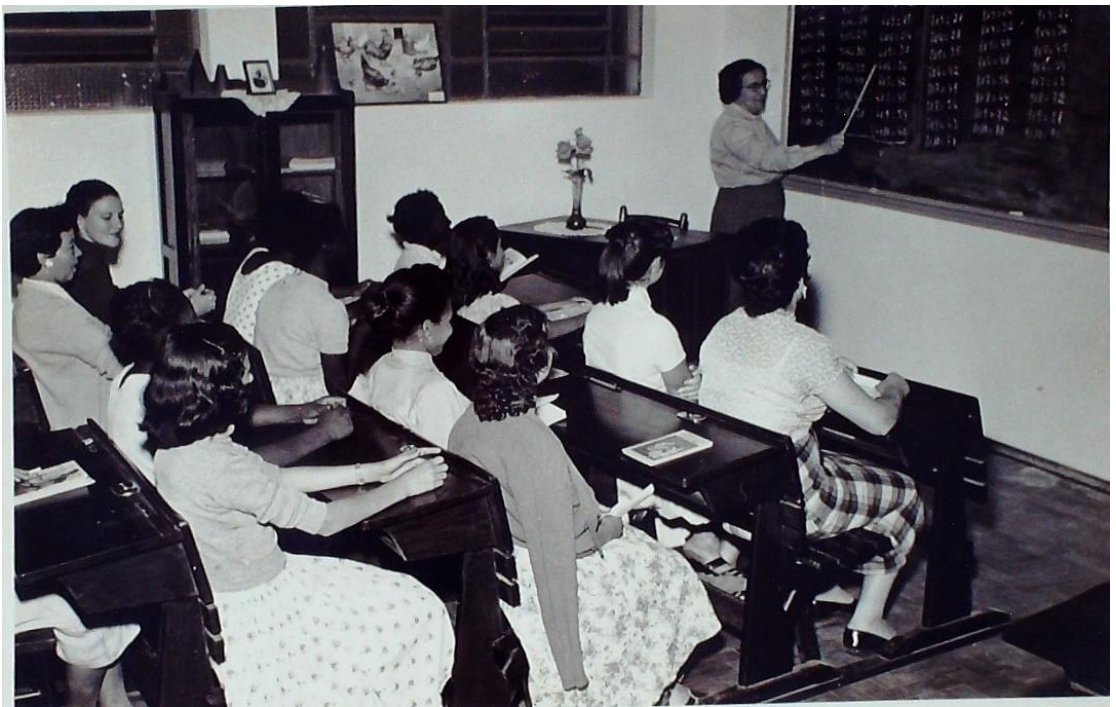

Fonte: Reprodução do Acervo da Escola Maria Antônia Luporine Sampaio. s/d.

Já em 2014, a exposição "Espaços escolares: reformas do ensino público na Primeira República" foi concebida a partir do acervo de fotografias pertencente à coleção Washington Luís, guardada no Museu Republicano "Convenção de Itu” da Universidade de São Paulo.

Sobre a doação da Coleção Washington Luís ao Museu:

[...] se inicia após o retorno do titular do exílio na Europa, entre os anos de 1930 a 1947. Em 1955 quando Washington Luis em visita a cidade de Itu para receber o título de cidadão ituano, os jornalistas Ermelindo Maffei e Ednam Mariano da Costa, segundo registros, solicitaram ao ex-presidente a doação de seu arquivo para o Museu Republicano.

Após seu falecimento em 1957, seu filho Victor comprometeu-se a doar a documentação para o Arquivo do Estado de São Paulo, que estava desenvolvendo o projeto intitulado "Titulares do Governo", com o objetivo de reunir documentos relacionados aos detentores de cargo político no estado de São Paulo, tendo encaminhado para aquela Instituição, a biblioteca e um conjunto de documentos relacionados com as atividades administrativas do período em que o titular desta coleção exerceu o cargo de presidente do estado de São Paulo.

Já o acervo encaminhado ao Museu Republicano foi doado por seu neto Cesar Luis, em dois períodos. Em 1989, foram doados os objetos e documentos textuais e, em 1995 a coleção de fotografias, composta por 4.753 (quatro mil, setecentos e cinqüenta e três) imagens, em preto e branco, destacando-se os registros de sua trajetória político-partidária, com ênfase nos eventos públicos relacionados a inaugurações de estradas de rodagem, prédios públicos e visitas oficiais. (BONNA; BRESSANIN; ZEQUINI, 2016, p. 5-6). 
Doado à instituição, em 1995, o conjunto iconográfico corresponde a 4884 imagens e traz informações sobre as visitas oficiais e as obras públicas inauguradas por Washington Luis ao longo de sua vida política.

A partir do trabalho de seleção e pesquisa em todo conjunto, o material, então exposto pela primeira vez, foi composto por reproduções de fotografias de escolas públicas em várias localidades paulistas, cujos edifícios davam visibilidade à educação, vista como propulsora do progresso e de uma sociedade civilizada nas primeiras décadas da República (1889-1930).

Estudos significativos foram produzidos nos últimos anos sobre a relação entre a escola e a arquitetura:

Por um lado, tanto se tem investigado a partir dos editais, inquéritos e programas de construção das escolas, ou seja, do que se diz sobre o prédio escolar, quando das suas plantas e fotografias. Por outro lado, ora dominam as análises os princípios de visibilidade que as construções escolares instauraram ao longo do tempo, sua materialidade e representatividade, ora se escoimam esses aspectos da monumentalidade em detrimento dos processos humanos que lhes conferem valor. Sobretudo, a importância que os grupos escolares tiveram na construção simbólica da escola primária tomou o centro dessas discussões. (PAULILO, 2019, p. 4).

Para a exposição "Espaços escolares: reformas do ensino público na Primeira República”, os estudos de Wolf (2010) e Souza (1998) foram questionadores para análise da Coleção Washington Luis e a reflexão sobre a política pública educacional empreendida pelos republicanos no início do século XX. 
FIGURA 11 - Abertura da Exposição: Espaços escolares: reformas do ensino público na primeira república. Sala temporária do Museu Republicano. 2014. Curadoria da Exposição: Supervisora Profa. Maria Aparecida de Menezes Borrego.

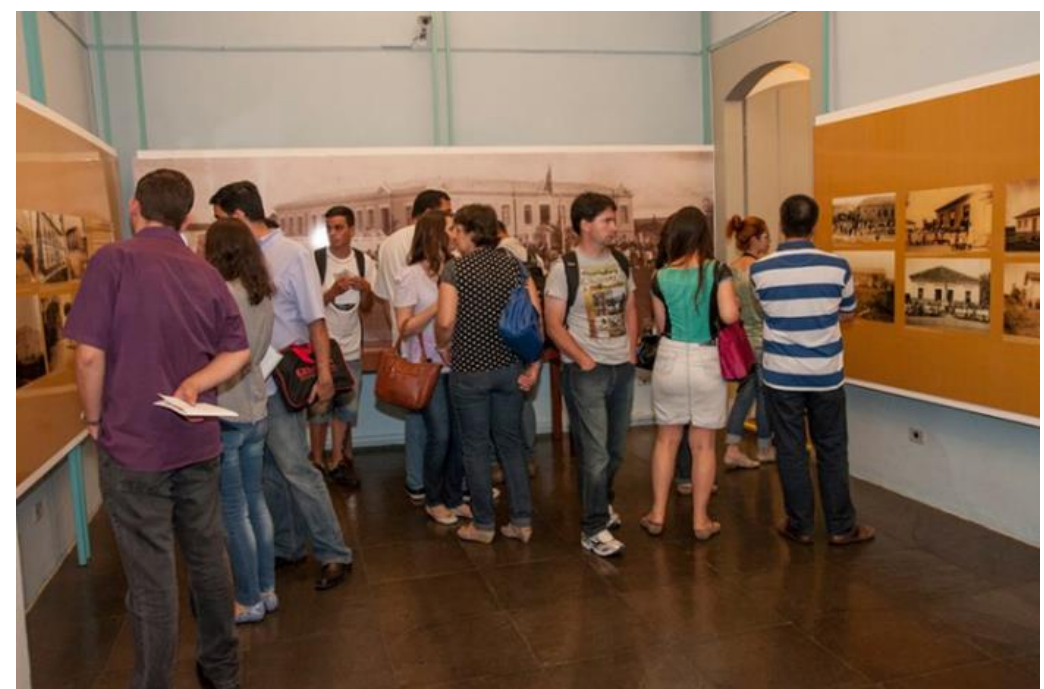

Fonte: Acervo digital do Museu Republicano Convenção de Itu/MP/USP. 2014.

Na Primeira República (1889-1930), intensificou-se o uso da fotografia como estratégia de documentação e divulgação das obras públicas. Álbuns fotográficos foram confeccionados reunindo o conjunto de realizações promovidas pelos poderes executivos em nível municipal, estadual e federal, entre as quais a construção de escolas públicas.

FIGURA 12 - Exposição: Espaços escolares: reformas do ensino público na primeira república. Sala temporária do Museu Republicano. 2014.

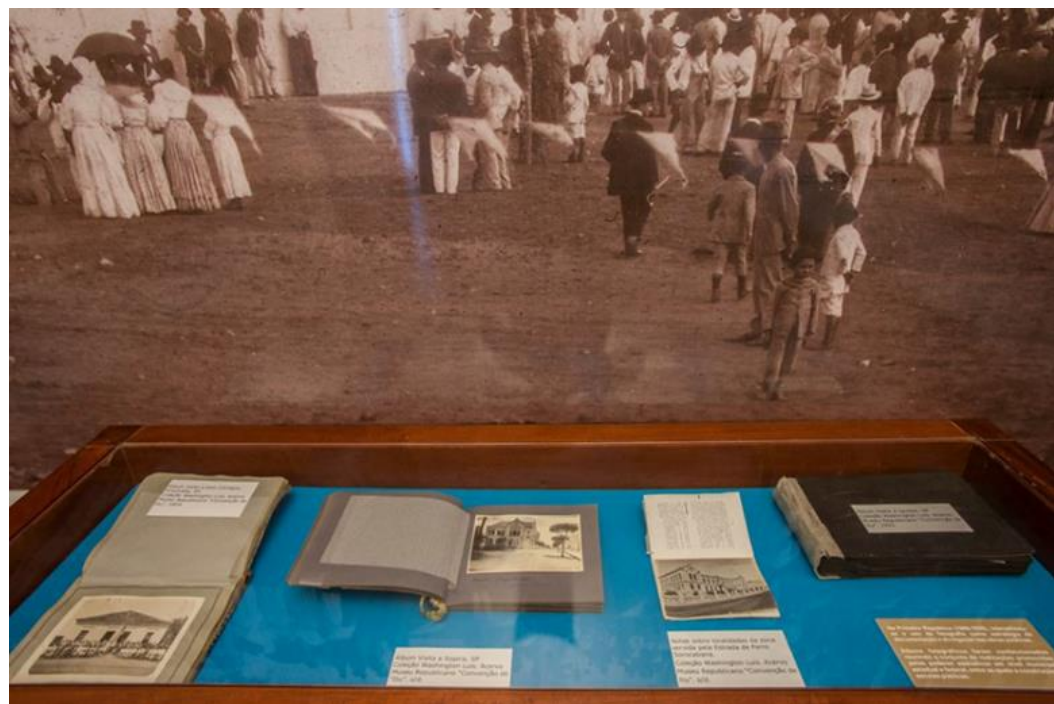

Fonte: Acervo digital do Museu Republicano Convenção de Itu/MP/USP. 2014. 
Paralelamente à exposição no Museu Republicano, foram abertas as mostras da Biblioteca, Objetos e Documentação no Centro de Estudos.

A equipe da biblioteca organizou a mostra de livros e jornais "Educação na Primeira República: fontes para pesquisa”. Já a equipe do arquivo fez a curadoria da exposição "O Colégio Nossa Senhora do Patrocínio de Itu na Coleção Helena e Verico Pinheiro", com imagens relacionadas à história do Colégio Nossa Senhora do Patrocínio de Itu, integrante da Coleção Helena e Verico Pinheiro.

Helena de Oliveira Machado foi estudante na década de 1910 no Colégio Nossa Senhora do Patrocínio da Cidade de Itu, a primeira instituição educacional católica fundada no Estado de São Paulo, destinado à educação feminina desde 1859.

Encontram-se nesta coleção, cadernos de desenhos, livros, recortes de jornais, álbuns de fotografias. A coleção foi doada pela neta de Helena ao Museu Republicano em 2010. Trata-se de um acervo rico para compreensão do cotidiano escolar da estudante.

FIGURA 13 - Caderno de desenhos de Helena de Oliveira Machado.

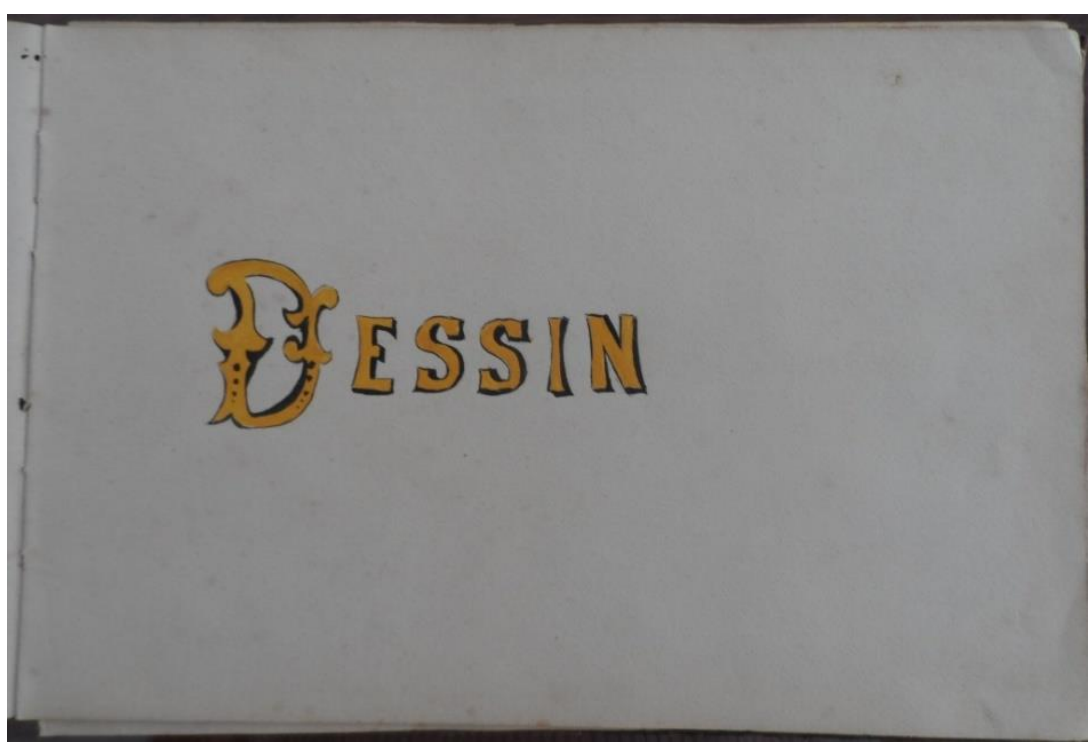

Fonte: Coleção Helena e Verico Pinheiro. 
FIGURA 14 - Caderno de desenhos de Helena de Oliveira Machado.

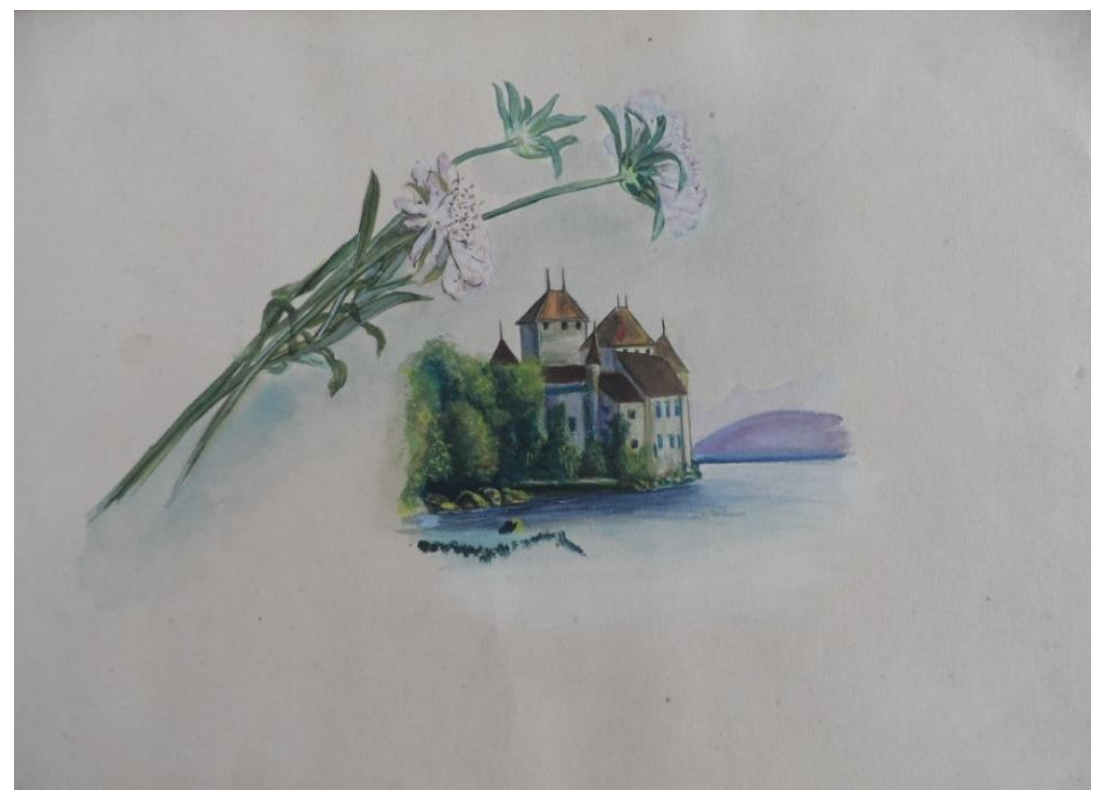

Fonte: Coleção Helena e Verico Pinheiro.

Por outro lado, agregou-se às mostras temporárias, outra relevante pesquisa, feita pela equipe do serviço de objetos sobre a Coleção de Ferramentas do Instituto Borges de Artes e Ofícios, que completava, também em 2014, 90 anos de existência. A exposição continha objetos e iconografias do cotidiano da instituição.

FIGURA 15 - Estudantes do IBAO.

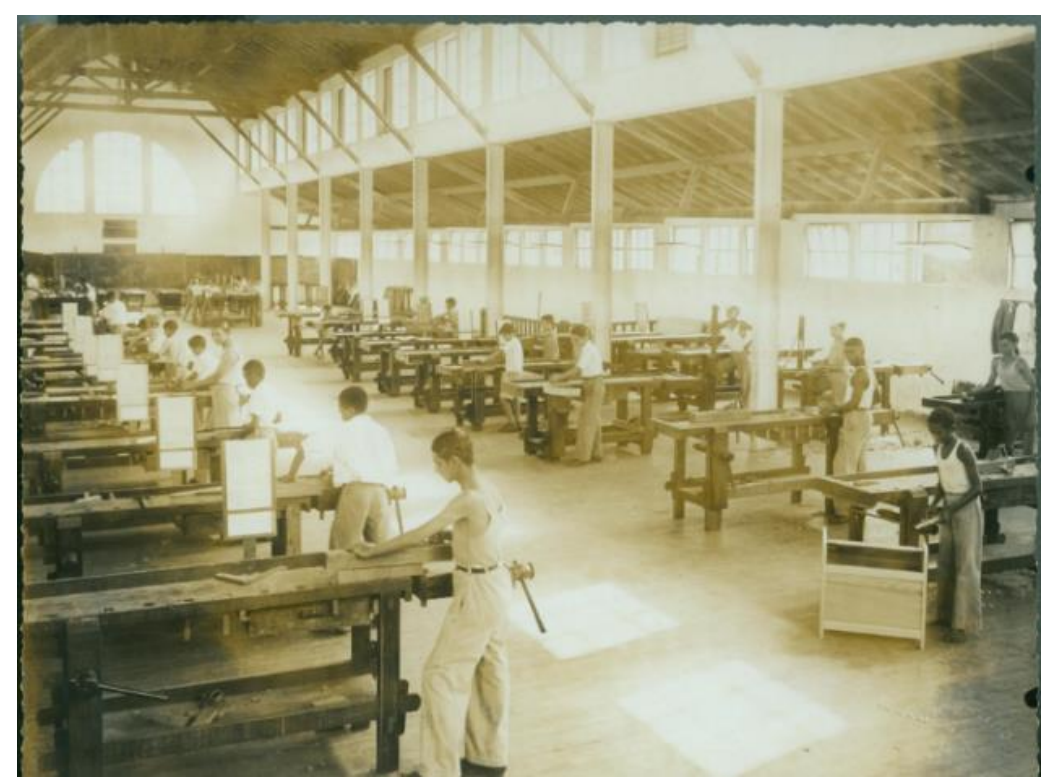

Fonte: Acervo Iconográfico do Museu Republicano/MP/USP. s/d. 
O Instituto Borges de Artes e Ofícios (IBAO) foi organizado em Itu pela Irmandade da Santa Casa de Misericórdia de Itu, em 28 de outubro de 1924, sendo instalado no edifício projetado por Ramos e Azevedo e seu escritório. Inicialmente funcionou com a formação de marcenaria e carpintaria, contudo, ao longo do tempo, formou tecnicamente inúmeros jovens em diversas áreas.

Por meio de nossa pesquisa sobre a aquisição destes acervos, encontramos no Serviço de Objetos do Museu Paulista que, em 24 de abril de 1991, o Instituto Borges de Artes e Ofícios ofereceu ao Museu Paulista da Universidade de São Paulo 189 (cento e oitenta e nove) peças, correspondentes a instrumentos de marcenaria, carpintaria, mecânica, barro e cerâmica que pertenceram ao instituto, em caráter definitivo. Os objetos foram doados, acompanhados de carta de doação, assinada pela coordenadora pedagógica e direcionada ao diretor do museu, professor Ulpiano Toledo Bezerra de Meneses.

Em ofício de agradecimento, datado de 27 de maio de 1991, Meneses acusa o recebimento da carta de doação "atendendo a solicitação nossa, a Santa Casa de Misericórdia de Itu informa que decidiu doar ao Museu Paulista da Universidade de São Paulo as ferramentas em duplicatas, em depósito no Instituto Borges de Artes e Ofícios - IBAO, de que a Santa Casa é mantenedora”. (Ofício de agradecimento da doação. Acervo do Museu Paulista da USP).

Continuando o ofício, destaca o significado destes objetos para o museu de história, ou seja, "Trata-se de colaboração do mais alto sentido, que trará enormes benefícios para o desenvolvimento de uma de nossas áreas prioritárias de atuação (O Universo do trabalho) e que representa honrosa confiança de V. Sas nesta instituição.” (Ofício de agradecimento da doação. Acervo Museu Paulista).

Nos fragmentos, o historiador e diretor do museu deixa documentar a articulação e o interesse inicial do museu pelo acervo, no momento em que se implantavam as linhas de pesquisas: história do trabalho, história cotidiano e sociedade, história do imaginário. Assim, o museu estruturava-se como produtor de conhecimento sobre a sociedade, a partir do estudo da cultura material.

Doados na década de 90 ao Museu Paulista e conservado no Ipiranga, ao integrar esta mostra, estes acervos foram primeiramente apresentados em exposição na cidade de Itu, próximos dos estudantes e da comunidade que os utilizaram. 
Dando continuidade à exposição "Espaços Escolares: reformas do ensino público na Primeira República”, inaugurada no próprio museu em novembro de 2014, que abordou os edifícios escolares existentes em várias localidades do Estado de São Paulo no período de 1889 a 1930, seguiu-se, em 2015, a exposição "Educação e escolas nas décadas iniciais da República” concebida a partir de livros didáticos, livros de matrícula, livros de atas de exames, jornais e fotografias das coleções Washington Luís e do Grupo Escolar Cesário Motta, pertencentes ao acervo do Museu Republicano "Convenção de Itu”, da Universidade de São Paulo. Foram explorados diversos materiais sobre os aspectos da renovação educacional proposta pelos republicanos relacionados aos programas de ensino, métodos pedagógicos, práticas cívico-militares, materiais didáticos e organização administrativa implantados nos estabelecimentos escolares paulistas em fins do século XIX e início do XX. Alguns exemplares da coleção de livros didáticos do período republicano existentes no arquivo do museu também foram apresentados na exposição.

FIGURA 16 - Exposição: Espaços Escolares: reformas do ensino público na Primeira República. Sala temporária do Museu Republicano. 2015. Curadoria da Exposição: Supervisora Profa. Maria Aparecida de Menezes Borrego.

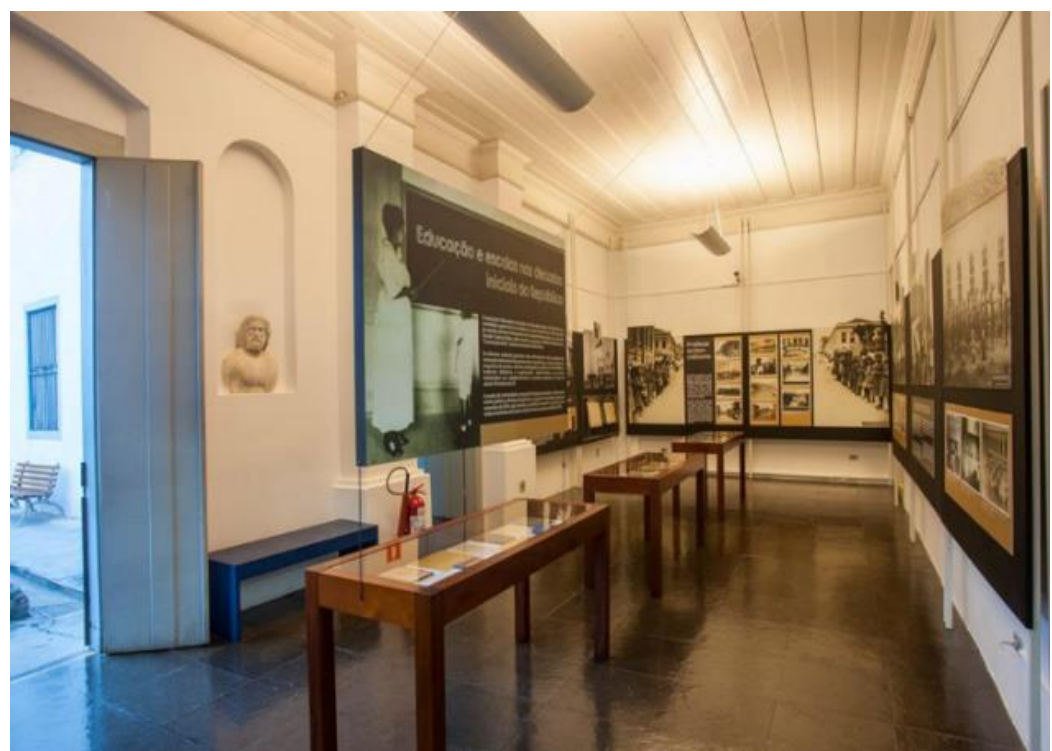

Fonte: Acervo digital do Museu Republicano Convenção de Itu/MP/USP. 2015.

Nota-se que os acervos do museu que possibilitam os estudos sobre a escola foram doados a partir da década de 1990, contexto em que os historiadores procuraram dar visibilidade aos vários atores do processo educativo. Outros, por sua vez, ampliaram essa perspectiva a partir de uma 
"procura social de identidade e de recuperação da memória em torno da escola" (MOGARRO, 200). Tais iniciativas contribuíram para suscitar questionamentos sobre a necessidade de valorizar e preservar os documentos que a escola foi produzindo ao longo de sua trajetória, compreendendose essa instituição nos marcos da organização da República (MOGARRO, 2005, p. 93).

Os cursos, palestras, seminários e encontros também foram fundamentais no processo de compartilhamento de conhecimento e para que tais acervos fossem reconhecidos pela comunidade. A partir deste reconhecimento foram estimuladas novas doações. Em novembro de 2014, a professora Maria Angela Pimentel Mangeon Elias doou para a biblioteca do museu vários livros de gramática francesa, inglesa e alemã, utilizados por sua irmã, quando era estudante do Colégio Patrocínio.

Por exemplo, Dona Maria Lúcia Caselli, que após visitar a exposição "Educação e Escolas nas décadas iniciais da República", em 2015, voltou ao museu acompanhada de uma carta de próprio punho, uma toalha e seis guardanapos bordados que havia prometido no dia de abertura da exposição.

Em sua carta relatou:

Toalha de chá bordada por Maria Lúcia Almeida de Marins e Dias, no ano de 1940, quando aluna do $3^{\circ}$ ano do Grupo Escolar "Dr. Cesário Motta", sob orientação da professora D. Luiza de Almeida Sampaio e que fez parte da exposição de trabalhos manuais daquele ano, no mencionado estabelecimento (Carta de Doação. Acervo do Museu Republicano).

Inspirada na exposição sobre o cotidiano escolar da cidade e de outras do Estado de São Paulo, Maria Lúcia tomou a decisão de tornar público o seu trabalho escolar, guardado durante anos em sua residência. Encontrou neste espaço um local possível de transformar sua memória individual em coletiva, como tantas outras pessoas que frequentaram os grupos escolares na primeira metade do século XX. 
FIGURA 17 - Exposição de trabalhos manuais do Grupo Escolar Cesário Motta.

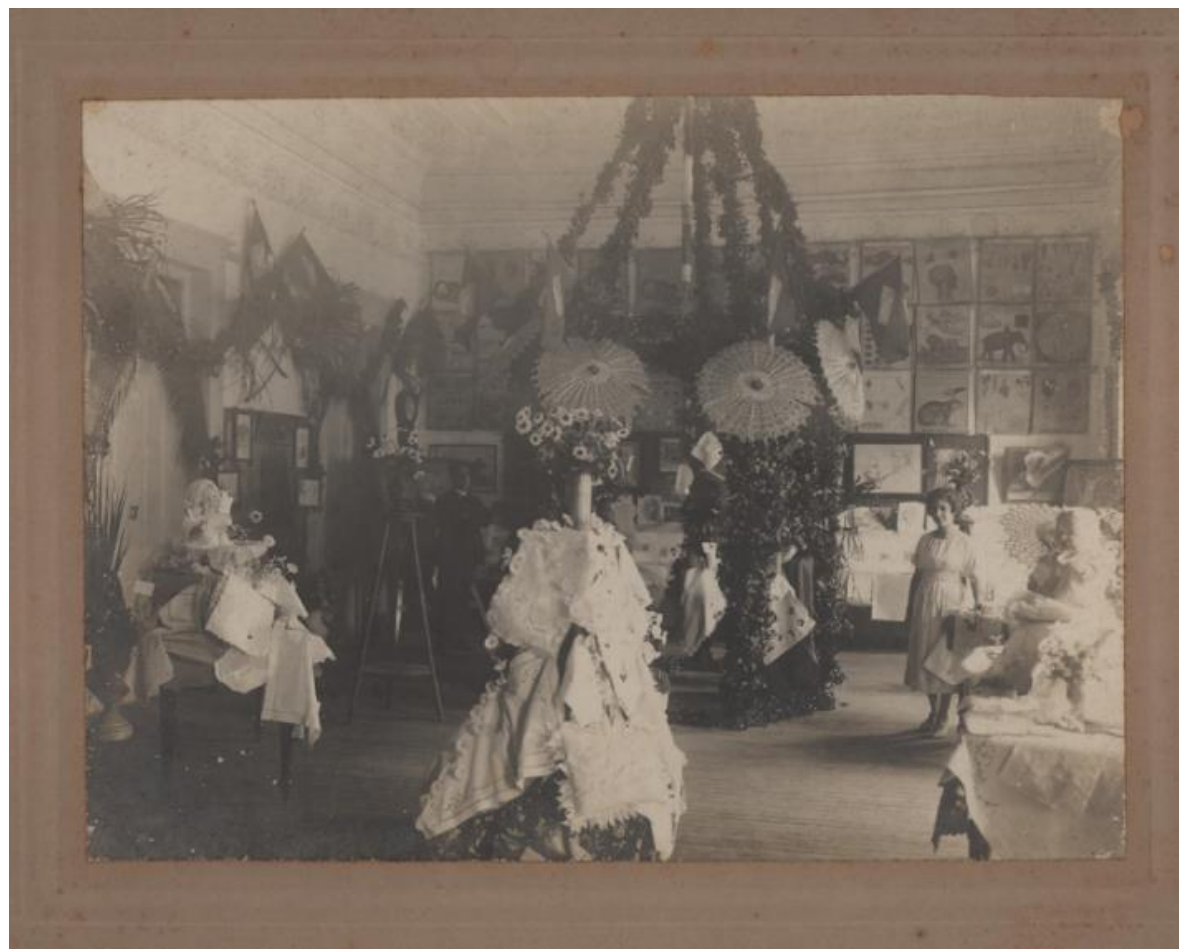

Fonte: Museu e Arquivo Histórico Municipal de Itu/MRCI/MP/USP. Fundo Grupo Escolar "Convenção de Itu”.

\section{CONSIDERAÇÕES FINAIS}

Logo, pode-se apontar dois grandes aspectos de valorização destes acervos escolares em instituições como o Museu Republicano. Por um lado, no processo de pesquisa, a troca com os estudiosos da história da educação e as novas abordagens, influenciaram os projetos e potencializaram a importância da salvaguarda destes acervos, trazendo novos olhares para antigos acervos e deslocando a relevância personificada dos integrantes do Partido Republicano Paulista de forma fetichizada.

Segundo Ulpiano Bezerra de Meneses, em "Memória e cultura material: documentos pessoais no espaço público",

O fetichismo consiste, precisamente, no deslocamento de sentidos das relações sociais - onde eles são efetivamente gerados - para os artefatos, criando-se a ilusão de sua autonomia e naturalidade. Por certo, tais atributos são historicamente selecionados e mobilizados pelas sociedades e grupos nas operações de produção, circulação e consumo de sentido. (MENESES, 1998, p. 91). 
Por outro aspecto, os acervos sobre e produzidos na escola integraram as coleções do museu na medida em que este, ao rever suas linhas de pesquisa sistematizadas em seu plano diretor de 1997, sob a direção do Prof. Ulpiano de Bezerra Meneses, mostrou-se interessado em problematizar a sociedade e integrar novas fontes à análise da cultura material.

Distinto do passado, em que os museus históricos brasileiros foram criados com o intuito de ressaltar a nacionalidade e considerava-se como objetos históricos exclusivamente àqueles “vinculados a fatos memoráveis da história do Brasil", na expressão do Decreto-lei 35, de 1937, que criou o órgão federal de proteção do patrimônio nacional, o museu histórico, segundo Menezes, “deve operar com os problemas históricos, isto é, problemas que dizem respeito à dinâmica das sociedades" (MENESES, 1994, p. 20).

\section{REFERÊNCIAS}

BREFE, Ana Claudia Fonseca. O Museu Paulista: Affonso de Taunay e a memória nacional. São Paulo: Editora UNESP: Museu Paulista, 2005.

CARVALHO, Roberto Machado. Memória de uma Escola: edição comemorativa do Cinquentenário da Escola Estadual "Regente Feijó", 1932- 1982, Itu, 1949.

MENESES, Ulpiano T. Bezerra de. A cidade como bem Cultural: Áreas envoltórias e outros dilemas, equívocos e alcance da preservação do patrimônio ambiental urbano. In: MORI, Victor et al. (Orgs). Patrimônio: atualizando o debate. São Paulo. 9ª SR/ IPHAN, 2006.

MENESES, Ulpiano T. Bezerra de. Do Teatro da Memória ao Laboratório da História: a exposição museológica e o conhecimento histórico. Anais do Museu Paulista, São Paulo, v. 2, p. 9-42, jan./dez. 1994.

MENESES, Ulpiano T. Bezerra de. Memória e cultura material: documentos pessoais no espaço público. Revista Estudos Históricos, v. 11, n. 21. 1998.

MOGARRO, Maria João. Arquivos e educação: a construção da memória educativa. Revista Brasileira de História da Educação, Sociedade Brasileira de História da Educação, 10. Jul./dez. 2005.

PAULILO, André Luiz. A cultura material da escola: apontamentos a partir da história da educação. Revista Brasileira de História da Educação, 2019. 
SOUZA, Rosa Fátima de. Tempos de civilização: a implantação da escola primária graduada no Estado de São Paulo (1890 - 1910). São Paulo: Editora UNESP, 1998.

TRILHA, Jaume. La educación fuero de la escuela: âmbitos nos formales y educación social. Barcelona: Editorial Ariel, 1996.

WOLFF, Silvia Ferreira Santos. Escolas para a República: Os Primeiros Passos da Arquitetura das Escolas Públicas Paulistas. São Paulo; EDUSP, 2010.

\section{FONTES:}

MUSEU E ARQUIVO HISTÓRICO MUNICIPAL DE ITU/MUSEU REPUBLICANO "CONVENÇÃO DE ITU"/MP/USP.

Fundo: Grupo Escolar Cesário Motta.

Fundo: Grupo Escolar Convenção de Itu.

\section{MUSEU PAULISTA DA USP}

Plano diretor de 1997.

Setor de objetos:

Coleção de Ferramentas do Instituto de Artes e Ofícios/ IBAO.

Ofício de agradecimento da doação da Coleção de Ferramentas do Instituto de Artes e Ofícios/ IBAO.

\section{MUSEU REPUBLICANO “CONVENÇÃO DE ITU”/MP/USP.}

Relatório de Aplicação de Recursos do Projeto Arquivo Escolar e Memória Social à Pró-Reitoria de Cultura e Extensão da Universidade de São Paulo, 2009.

Relatórios Institucional do MRCI de 2008 - 2016.

Documentação textual e iconográfica do Museu Republicano “Convenção de Itu”/MP/USP.

Coleção Helena e Verico Pinheiro

Coleção Washington Luís

Catálogo da Coleção Washington Luís feita por Anicleide Zequini, Daisy Aparecida Ferraz de Bonna e Melissa Stecca Bressanin. 2016.

Setor de objetos:

Camiseta da Escola Municipal "Convenção de Itu”. 
Coleção de têxteis - Toalha e 6 guardanapos bordados. Doadora: Maria Lúcia Almeida de Marins e Dias.

Carta de doação escrita de próprio punho por Maria Lúcia Almeida de Marins e Dias sobre a doação da Toalha e 6 guardanapos bordados.

Recebido em: 12 de junho de 2020 Aceito em: 01 de março de 2021 